\title{
The impact of preoperative endoscopic ultrasound on the surgical management of pancreatic neuroendocrine tumours
}

\author{
Fahad Alsohaibani MD FRCPC ${ }^{1}$, David Bigam MD FRCSC ${ }^{2}$, Norman Kneteman MD FRCSC ${ }^{2}$, \\ AM James Shapiro MD FRCSC ${ }^{2}$, Gurpal Singh Sandha MBBS FRCPC ${ }^{1}$
}

F Alsohaibani, D Bigam, N Kneteman, AMJ Shapiro, GS Sandha. The impact of preoperative endoscopic ultrasound on the surgical management of pancreatic neuroendocrine tumours. Can J Gastroenterol 2008;22(10):817-820.

BACKGROUND: Endoscopic ultrasound (EUS) is accurate in diagnosing pancreatic neuroendocrine tumours (PNETs), but its impact on surgical management is unclear.

OBJECTIVE: To determine whether preoperative EUS findings altered the decision for, and extent of, surgery in patients with PNETs.

METHODS: A retrospective review of patients referred for EUS because of suspected PNETs was conducted. The diagnosis of PNETs was confirmed by EUS-guided fine needle aspiration cytology, where indicated, or by surgical histology. EUS findings were compared with computed tomography (CT) findings to determine whether there was an impact on the decision for surgical management.

RESULTS: Fourteen patients (10 women), with a mean age of 44 years, underwent EUS for suspected PNETs. PNETs were seen with CT in 10 of 13 patients (77\%) and with EUS in 14 of 14 patients $(100 \%)$. One obese patient could not fit into the CT scanner. This patient had five PNETs on EUS. Three patients with a normal CT scan were determined to have one or two PNETs on EUS. Three patients with one or two PNETs on CT were found to have five to eight PNETs on EUS. EUS altered the decision for possible surgical management in five of 14 patients (36\%), either by identifying a PNET or by finding multiple and multifocal PNETs that were not visualized on CT scans.

CONCLUSION: EUS is useful in the preoperative assessment of PNETs by providing information that significantly influences the decision for surgical intervention or changes the extent of the planned surgery.

Key Words: Biopsy; Endosonography; Neuroendocrine tumour; Outcome; Pancreas

Dancreatic neuroendocrine tumours (PNETs) are relatively uncommon and account for only $1 \%$ to $2 \%$ of all pancreatic neoplasms (1). They are commonly discovered between the fourth and fifth decades of life, with a slight female predominance (2).

PNETs can occur sporadically or may be associated with inherited syndromes, such as multiple endocrine neoplasia type 1 (MEN1), von Hippel-Lindau disease, von Recklinghausen disease and tuberous sclerosis (3). Up to $30 \%$ of patients with MEN1 have clinically apparent PNETs or gastrointestinal neuroendocrine tumours. However, subclinical involvement can be demonstrated in up to $80 \%$ of patients (4).

\section{Les répercussions de l'endoscopie préopértoire sur la prise en charge chirurgicale des tumeurs neuroendocriniennes du pancréas} HISTORIQUE : L'endoscopie est une méthode précise pour diagnosti-
quer les tumeurs neuroendocriniennes du pancréas (TNEP), mais on n'en
connaît pas exactement les répercussions sur la prise en charge chirurgi-
cale.

OBJECTIF : Déterminer si les résultats des endoscopies préopératoires modifient la décision d'opérer les patients atteints de TNEP et l'importance de la chirurgie.

MÉTHODOLOGIE : Les auteurs ont procédé à une analyse rétrospective des patients aiguillés en vue de subir une endoscopie à cause de TNEP présumées. Le diagnostic de TNEP était confirmé au moyen d'une cytologie par aspiration à l'aiguille guidée par endoscopie, au besoin, ou d'une histologie chirurgicale. Les auteurs ont comparé les résultats de l'endoscopie à ceux de la tomodensitométrie pour déterminer si la première avait des répercussions sur la décision de prise en charge chirurgicale.

RÉSULTATS : Quatorze patients (dix femmes) d'un âge moyen de 44 ans ont subi une endoscopie à cause de TNEP présumées. La tomodensitométrie a révélé des TNEP chez dix des 13 patients ( $77 \%$ ) et l'endoscopie, chez 14 des 14 patients ( $100 \%$ ). Un patient obèse ne pouvait pénétrer dans le tomodensitomètre. Ce patient avait cinq TNEP selon l'endoscopie. Chez trois patients dont la tomodensitométrie était normale, l'endoscopie a révélé une ou deux TNEP. Trois patients ayant une ou deux TNEP à la tomodensitométrie en avaient de cinq à huit à l'endoscopie. L'endoscopie a modifié la décision de possibilité de prise en charge chirurgicale chez cinq des 14 patients (36\%), que ce soit à cause de la découverte de TNEP ou de TNEP multiples et multifocales qu'on n'avait pas vues à la tomodensitométrie.

CONCLUSION : L'endoscopie est utile pour l'évaluation préopératoire de TNEP parce qu'elle fournit de l'information qui influe de manière significative sur la décision d'intervention chirurgicale ou qu'elle modifie l'importance de l'opération prévue.

Gastrinomas and insulinomas are the most common functional PNETs in MEN1, accounting for $40 \%$ and $10 \%$ of patients, respectively (5).

Because PNETs are slow-growing tumours, their prognosis is good, and many patients can be cured with surgical resection. Despite various radiographic imaging techniques, such as transabdominal ultrasound, computed tomography (CT), magnetic resonance imaging (MRI), positron emission tomography and octreotide scintigraphy, up to $30 \%$ of PNETs can be missed during preoperative evaluation (6). Published data suggest the superiority of endoscopic ultrasound (EUS) in detecting and localizing PNETs, particularly those smaller

${ }^{1}$ Department of Medicine; ${ }^{2}$ Department of Surgery, University of Alberta, Edmonton, Alberta

Correspondence: Dr Gurpal Singh Sandha, Division of Gastroenterology, Zeidler Ledcor Centre, 130 University Campus, Edmonton, Alberta

T6G 2X8. Telephone 780-492-8170, fax 780-492-1699, e-mail gurpal.sandha@ualberta.ca

Received for publication June 10, 2008. Accepted July 11, 2008 

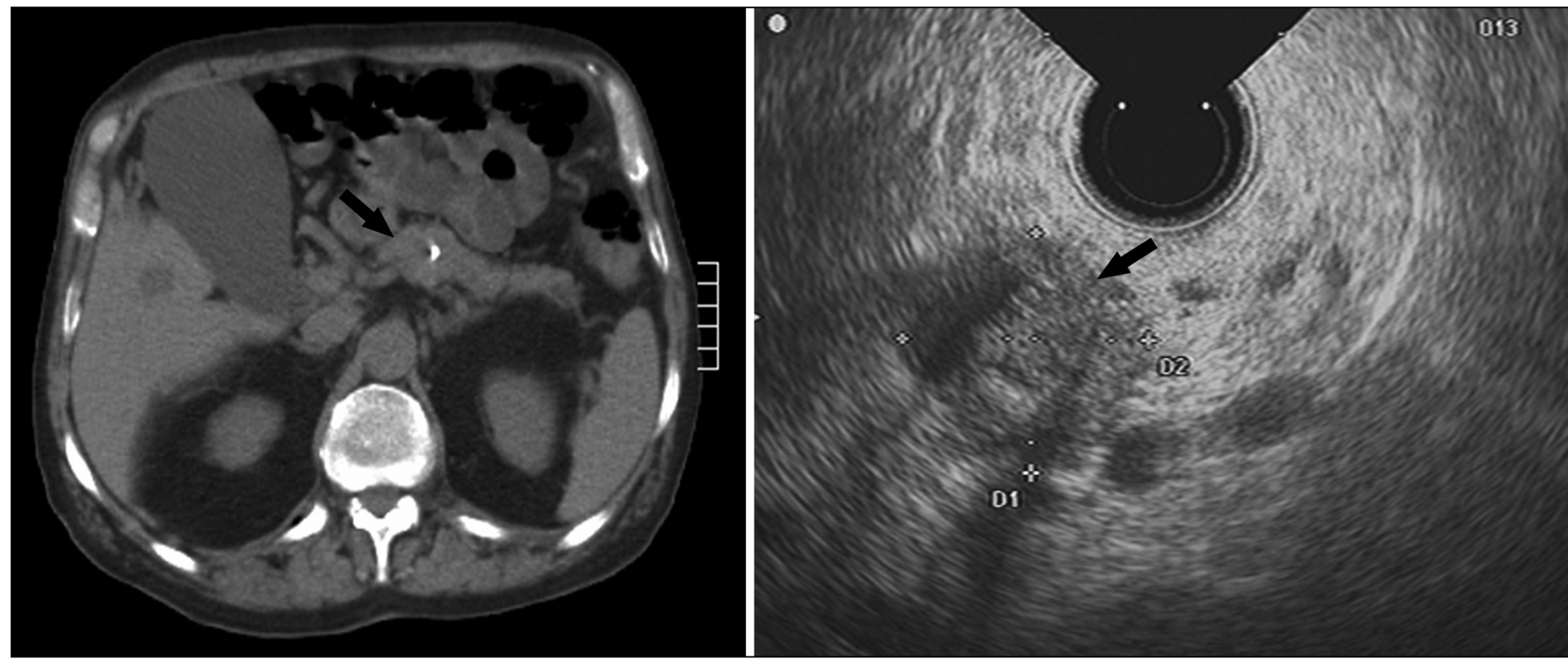

Figure 1) Left panel Computed tomography image showing a 'calcified' focus within the body of a pancreas, but no definite mass was reported (arrow). Right panel Endosonographic image showing a discrete hypoechoic mass (arrow) within the body of a pancreas. Endoscopic ultrasound-guided fine needle aspiration from a mass reported as a neuroendocrine tumour

than $2 \mathrm{~cm}$ in size, compared with ultrasound, CT, MRI and endoscopic retrograde cholangiopancreatography (7-9). In asymptomatic patients with MEN1, EUS was able to identify $82 \%$ of PNETs before the development of significant biochemical test abnormalities (4). EUS alone has a limited ability to differentiate between benign and malignant PNETs, but the diagnostic accuracy can be enhanced with EUS-guided fine needle aspiration (FNA), which can be performed in most patients (10). Despite the usefulness of EUS performed with or without FNA as an accurate diagnostic tool, there are limited data regarding its impact on the change in surgical management of PNETs.

The goal of the present study was to assess the impact of preoperative EUS on the decisions regarding surgical management of patients with PNETs.

\section{METHODS}

\section{Patients}

A retrospective chart review of patients with suspected PNETs who underwent EUS at the University of Alberta Hospital (Edmonton, Alberta) between February 2004 and January 2008 was performed. The diagnosis of PNETs was confirmed by EUS-guided FNA cytology and subsequent surgical pathology, where resection was indicated. Patients who were confirmed to have metastatic disease and were still considered for possible surgery had a tissue diagnosis obtained from the metastatic lesion and therefore may not have had EUS-FNA cytology or surgical histology. Relevant data, including patient demographics, radiographic imaging and surgical histology, were collected.

\section{EUS examination}

During the study period, all EUS procedures were performed by a single experienced endosonographer (Dr Sandha; experience with more than 1250 EUS procedures) using the Pentax EG3630UR radial echoendoscope (Pentax Precision Instruments, USA). PNETs were seen as well-encapsulated, homogeneous and isoechoic or slightly hypoechoic masses (Figure 1). When necessary, EUS-FNA was performed using the Pentax EG3630U or EG3630UT curvilinear array echoendoscope (Pentax Precision Instruments, USA) and a 22-gauge Wilson-Cook Echotip or Echotip-Ultra needle (Wilson-Cook Medical Inc, USA). All patients provided informed consent before undergoing the procedure. Procedures were performed in the endoscopy unit under conscious sedation with midazolam and meperidine.

\section{Ethics}

The study was approved by the Health Research Ethics Board at the University of Alberta, including a chart review of all patients.

\section{RESULTS}

Between February 2004 and January 2008, 14 patients suspected of having a PNET based on clinical features and/or radiographic imaging underwent EUS with or without FNA. The patient population included 10 women $(71 \%)$, and the mean age of the study group was 44 years (range 23 to 69 years). Eight patients (57\%) were known to have MEN1. The size of PNETs ranged from $0.4 \mathrm{~cm}$ to $2.5 \mathrm{~cm}$ in maximum diameter (Table 1). Most of the tumours were located in the body and/or tail of the pancreas (12 of 14 patients [86\%]).

CT was performed in 13 of 14 patients and suggested the presence of a PNET in 10 of 13 patients (77\%). Of these, nine patients had vascular enhancing lesions suggestive of a PNET. One morbidly obese patient could not fit into the CT scanner. Other imaging modalities performed included MRI in six of 14 patients with a PNET seen in four of six patients $(67 \%)$ and an octreotide scan in eight of 14 patients, with a PNET identified in four of eight patients (50\%).

EUS identified a PNET in 14 of 14 patients (100\%). EUSFNA was performed in 10 of 14 patients, with positive cytology in nine of 10 patients (90\%). EUS-FNA cytology or surgical pathology confirmed EUS findings of a PNET in 12 of 14 patients. Two patients did not have EUS-FNA cytology or surgical histology to confirm the diagnosis because of the presence of metastatic disease to liver and lung, respectively, documented by tissue diagnosis. 
TABLE 1

Demographic data of patient cohort

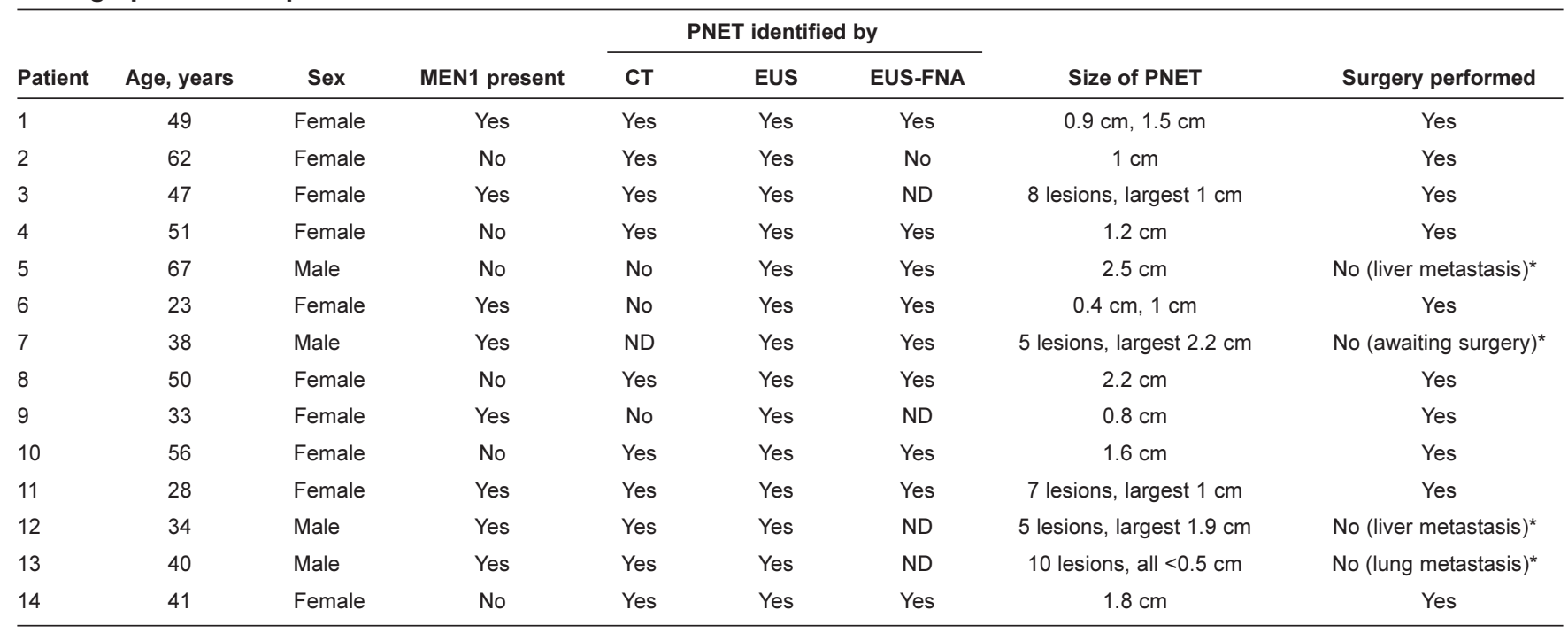

${ }^{*}$ Reason surgery was not performed. CT Computed tomography; EUS Endoscopic ultrasound; EUS-FNA EUS-guided fine needle aspiration; MEN1 Multiple endocrine neoplasia type 1; ND Not done; PNET Pancreatic neuroendocrine tumour

The morbidly obese patient who could not have a CT scan was found to have five PNETs on EUS. These were confirmed by EUS-FNA. Three patients (two of whom had MEN1) reported to have a normal CT were found to have one or two PNETs by EUS. The PNETs were confirmed by EUS-FNA and/or surgical pathology. In three other patients, in whom CT identified one or two PNETs, preoperative EUS found five to eight PNETs, resulting in a change in the extent of the planned surgery from distal pancreatectomy to total pancreatectomy.

A definite diagnosis of a PNET or the finding of multiple and/or multifocal PNETs, not seen or appreciated on a CT scan, was only made during preoperative EUS in seven of 14 patients (50\%). One of these patients (patient 7 in Table 1) was currently awaiting surgery. Another patient (patient 5 in Table 1) was not considered for surgery when subsequent metastasis to the liver was found. Surgical intervention was also not performed in a young patient (patient 12 in Table 1) who was initially considered for aggressive surgery despite having documented metastasis. Overall, the information obtained with a preoperative EUS examination had a definite impact on the decision for surgical intervention for PNETs in five of 14 patients (36\%).

\section{DISCUSSION}

Neuroendocrine tumours are a heterogeneous group of neoplasms that originate from a common precursor cell population that shares a number of antigens with nerve elements, such as neuron-specific enolase and chromogranins (11). PNETs are uncommon tumours of the pancreas, accounting for only $1 \%$ to $2 \%$ of all primary pancreatic neoplasms. The incidence of PNETs has been estimated to be approximately 0.4 to 1.0 in 100,000 people. However, in autopsy and surgical series, up to $15 \%$ of pancreatic neoplasms have been identified as PNETs $(11,12)$.

Most PNETs are well- to moderately differentiated, and can be classified as those associated with a clinical syndrome caused by excessive hormone production (functional or syndromic PNETs) or those without such an association (nonfunctional or nonsyndromic PNETs) (13). Between $70 \%$ and $85 \%$ of
PNETs are functional, with insulinomas accounting for $40 \%$ to $60 \%$ and gastrinomas accounting for $20 \%$ to $30 \%$.

PNETs vary in size, ranging from smaller than $1 \mathrm{~cm}$ to $5 \mathrm{~cm}$ or larger, and are benign in up to $40 \%$ of cases. Differentiation between benign and malignant PNETs can be difficult, although the presence of local invasion of adjacent organs or distant metastasis usually indicates malignant behaviour $(14,15)$. Even in the face of metastatic disease, the prognosis of PNETs is more favourable than the more common pancreatic adenocarcinoma. Hence, a stepwise preoperative evaluation for PNET localization is very important for potentially curative surgery.

Despite the advances in imaging modalities, up to $30 \%$ of PNETs can be missed during a preoperative assessment. The sensitivity of transabdominal ultrasound for detecting PNETs ranges from $20 \%$ to $86 \%$ and increases with tumour size (16). Similarly, the sensitivity of nonhelical CT of the abdomen is reported to be $30 \%$ if the size of the primary tumour is between $1 \mathrm{~cm}$ and $3 \mathrm{~cm}$, and $95 \%$ if it is larger than $3 \mathrm{~cm}$, although a primary tumour smaller than $1 \mathrm{~cm}$ is rarely detected. The sensitivity of a CT scan can be enhanced using a multiphase and multidetector CT scanner. MRI is just as accurate as a CT scan for localizing PNETs. As with ultrasound and CT, tumour detection using MRI increases with tumour size. The overall sensitivity of MRI is between $85 \%$ and $94 \%$, with a specificity of $78 \%$ to $100 \%$ (16-18). Because $80 \%$ to $90 \%$ of neuroendocrine tumours have somatostatin receptors, octreotide scintigraphy could potentially be the initial imaging procedure of choice. However, there are pitfalls in localizing small tumours and tumours that lack somatostatin receptors (19). Because these modalities are not accurate enough for preoperative visualization and identification of PNETs in the pancreas, which is paramount in planning the extent of surgery, intraoperative ultrasound (IOUS) has been used for direct examination of the pancreas (20). In this study (20), IOUS was found to localize $96 \%$ of PNETs and $58 \%$ of non-PNETs. The authors concluded that IOUS altered surgical management in $11 \%$ of gastrinomas, mainly by identifying additional gastrinomas or determining that the gastrinoma was malignant. 
However, this modality requires laparoscopy or laparotomy, and decisions regarding the extent of surgical intervention required cannot easily be made and discussed with patients preoperatively.

EUS enables a high-frequency ultrasound probe to be placed in close proximity to the pancreas. Compared with other imaging modalities, EUS was more accurate in detecting and localizing PNETs, especially those smaller than $2.5 \mathrm{~cm}$, with an overall accuracy between $89 \%$ and $97 \%$ (21-24). Varas Lorenzo et al (6) compared preoperative EUS with transabdominal ultrasound, CT, MRI, angiography and OctreoScan (Mid-South Imaging and Therapeutics, USA) in 37 patients suspected to have gastrointestinal neuroendocrine tumours. The sensitivity and specificity of EUS was $78 \%$ and $80 \%$, respectively. EUS detected three PNETs (all insulinomas) that were smaller than $1 \mathrm{~cm}$ in size, which were missed by ultrasound, CT and MRI (6). In most cases, adding EUS-FNA to a basic EUS examination enhances the sensitivity of EUS by providing a cytological diagnosis without the risk of significant complications or the need for exploratory surgery (25). Jani et al (9) recently reported 41 patients with PNETs diagnosed by EUS-guided FNA. Interestingly, 85\% of the tumours were nonfunctional and all of these nonfunctional tumours were discovered incidentally on CT scan. Surgical resection was performed in $78 \%$ of cases. Precise localization of the tumours in the body or the tail of the pancreas by EUS led to laparoscopic resection of these tumours in $34 \%$ of patients. Nine patients $(22 \%)$ did not undergo surgery because of tumour metastasis, significant medical comorbidity or patient refusal (9).
Our study has some obvious limitations. It was a singlecentre, retrospective review of a relatively small number of patients. However, our results suggest that preoperative EUS had a significant impact on the possible surgical management of $50 \%$ of patients and on definite surgical management in $36 \%$ of patients suspected of having PNETs. Patients with PNETs identified by EUS were then scheduled for surgery, and those who were found to have multiple and multifocal lesions underwent total pancreatectomy, instead of distal pancreatectomy, which was planned originally based on standard radiographic imaging. We currently do not routinely perform EUS-guided FNA in PNETs. This procedure is indicated only for those patients in whom a neuroendocrine tumour or syndrome, such as MEN1, is in doubt or when a CT scan has failed to localize a mass but one is suspected based on biochemical abnormalities.

Our results suggest that EUS with or without FNA is a very helpful diagnostic tool in the preoperative assessment of patients suspected of having PNETs, particularly in patients at risk for multifocal disease such as those with MEN1. The information obtained is important for surgeons to plan surgery in advance and preoperatively discuss the appropriate procedure with the patients.

ACKNOWLEDGEMENTS: The authors wish to acknowledge Mr Stephen Wreakes, Medical Photographer, Capital Health, for his assistance with the photographic images. The present study was presented as a poster at Canadian Digestive Diseases Week, February 29 to March 3, 2008, Montreal, Quebec.

\section{REFERENCES}

1. Barakat MT, Meeran K, Bloom SR. Neuroendocrine tumours. Endocr Relat Cancer 2004;11:1-18.

2. Jani N, Moser AJ, Khalid A. Pancreatic endocrine tumors. Gastroenterol Clin North Am 2007;36:431-9.

3. Frankel WL. Update on pancreatic endocrine tumors. Arch Pathol Lab Med 2006;130:963-6.

4. Wamsteker EJ, Gauger PG, Thompson NW, Scheiman JM. EUS detection of pancreatic endocrine tumors in asymptomatic patients with type 1 multiple endocrine neoplasia. Gastrointest Endosc 2003;58:531-5.

5. Trump D, Farren B, Wooding C, et al. Clinical studies of multiple endocrine neoplasia type 1 (MEN1). QJM 1996;89:653-69.

6. Varas Lorenzo MJ, Miquel Collell JM, Maluenda Colomer MD, Boix Valverde J, Armengol Miro JR. Preoperative detection of gastrointestinal neuroendocrine tumors using endoscopic ultrasonography. Rev Esp Enferm Dig 2006;98:828-36.

7. Rosch T, Lorenz R, Braig C, et al. Endoscopic ultrasound in pancreatic tumor diagnosis. Gastrointest Endosc 1991;37:347-52.

8. Muller MF, Meyenberger C, Bertschinger P, Schaer R, Marincek B. Pancreatic tumors: Evaluation with endoscopic US, CT, and MR imaging. Radiology 1994;190:745-51.

9. Jani N, Khalid A, Kaushik N, et al. EUS-guided FNA diagnosis of pancreatic endocrine tumors: New trends identified. Gastrointest Endosc 2008;67:44-50.

10. Ardengh JC, Lopes CV, de Lima LF, et al. Diagnosis of pancreatic tumors by endoscopic ultrasound-guided fine-needle aspiration. World J Gastroenterol 2007;13:3112-6.

11. Simon P, Spilcke-Liss E, Wallaschofski H. Endocrine tumors of the pancreas. Endocrinol Metab Clin North Am 2006;35:431-47.

12. Wick MR, Graeme-Cook FM. Pancreatic neuroendocrine neoplasms: A current summary of diagnostic, prognostic, and differential diagnostic information. Am J Clin Pathol 2001;115(Suppl):S28-45.

13. Iacobuzio-Donahue CA, Montgomery EA. Gastrointestinal and Liver Pathology. Edinburgh: Churchill Livingstone, 2006.

14. Kloppel G, Heitz PU. Pancreatic endocrine tumors. Pathol Res Pract 1988;183:155-68.

15. Schindl M, Kaczirek K, Kaserer K, Niederle B. Is the new classification of neuroendocrine pancreatic tumors of clinical help? World J Surg 2000;24:1312-8.

16. Rockall AG, Reznek RH. Imaging of neuroendocrine tumours (CT/MR/US). Best Pract Res Clin Endocrinol Metab 2007;21:43-68.

17. Thoeni RF, Mueller-Lisse UG, Chan R, Do NK, Shyn PB. Detection of small, functional islet cell tumors in the pancreas: Selection of MR imaging sequences for optimal sensitivity. Radiology 2000;214:483-90.

18. Owen NJ, Sohaib SA, Peppercorn PD, et al. MRI of pancreatic neuroendocrine tumours. Br J Radiol 2001;74:968-73.

19. Oberg K, Eriksson B. Endocrine tumours of the pancreas. Best Pract Res Clin Gastroenterol 2005;19:753-81.

20. Norton JA, Cromack DT, Shawker TH, et al. Intraoperative ultrasonographic localization of islet cell tumors. A prospective comparison to palpation. Ann Surg 1988;207:160-8.

21. Rosch T, Lightdale CJ, Botet JF, et al. Localization of pancreatic endocrine tumors by endoscopic ultrasonography. N Engl J Med 1992;326:1721-6.

22. Palazzo L, Roseau G, Chaussade S, Salmeron M, Gaudric M, Paolaggi JA. [Pancreatic endocrine tumors: Contribution of ultrasound endoscopy in the diagnosis of localization.] Ann Chir 1993;47:419. 24.

23. Zimmer T, Stolzel U, Bader M, et al. Endoscopic ultrasonography and somatostatin receptor scintigraphy in the preoperative localisation of insulinomas and gastrinomas. Gut 1996;39:562-8.

24. Anderson MA, Carpenter S, Thompson NW, Nostrant TT, Elta GH, Scheiman JM. Endoscopic ultrasound is highly accurate and directs management in patients with neuroendocrine tumors of the pancreas. Am J Gastroenterol 2000;95:2271-7.

25. Lachter J, Cooperman JJ, Shiller M, et al. The impact of endoscopic ultrasonography on the management of suspected pancreatic cancer - a comprehensive longitudinal continuous evaluation. Pancreas 2007;35:130-4. 


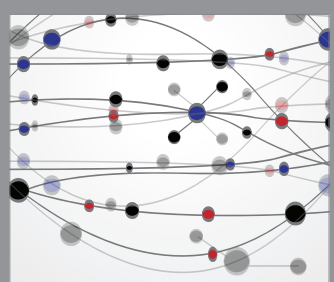

The Scientific World Journal
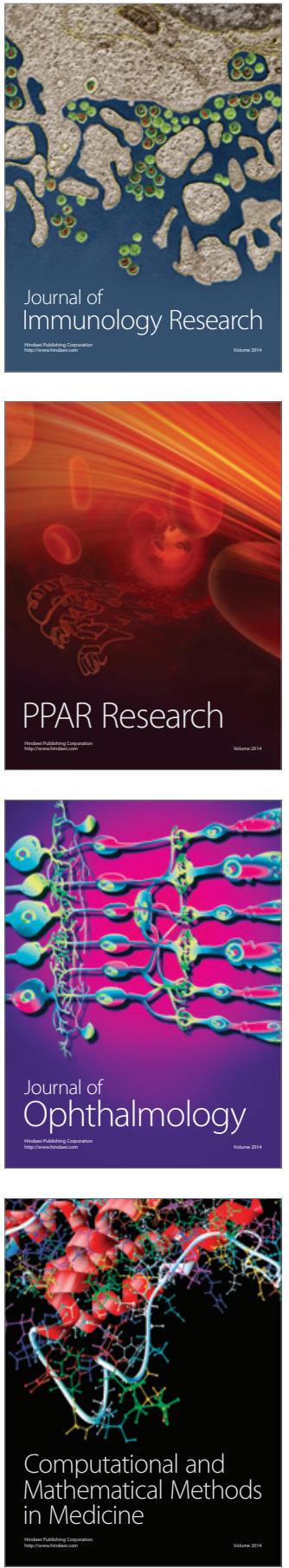

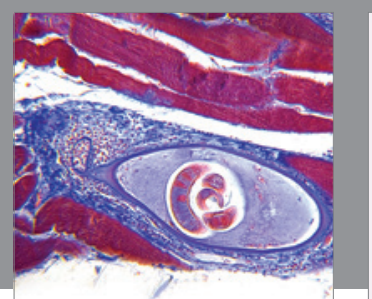

Gastroenterology Research and Practice

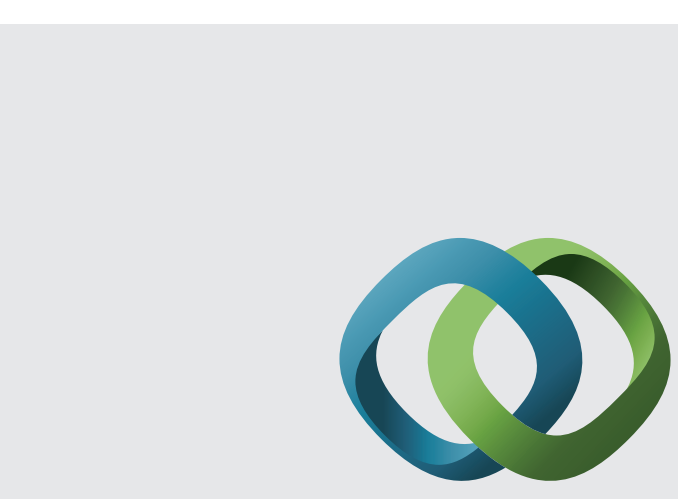

\section{Hindawi}

Submit your manuscripts at

http://www.hindawi.com
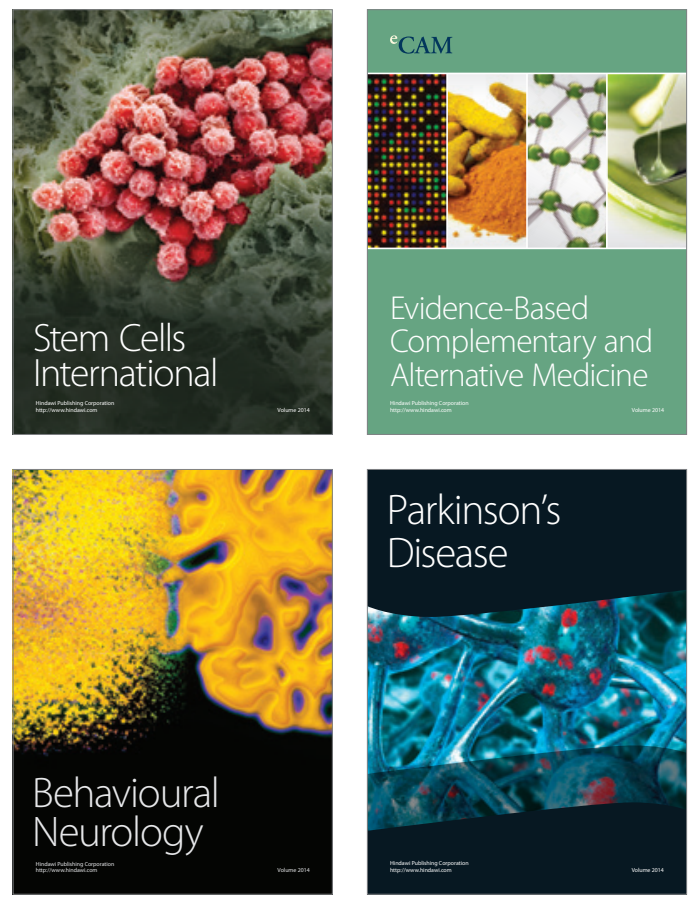
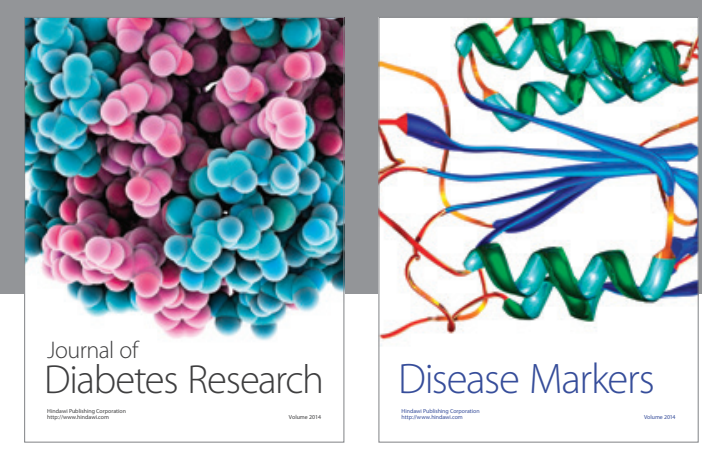

Disease Markers
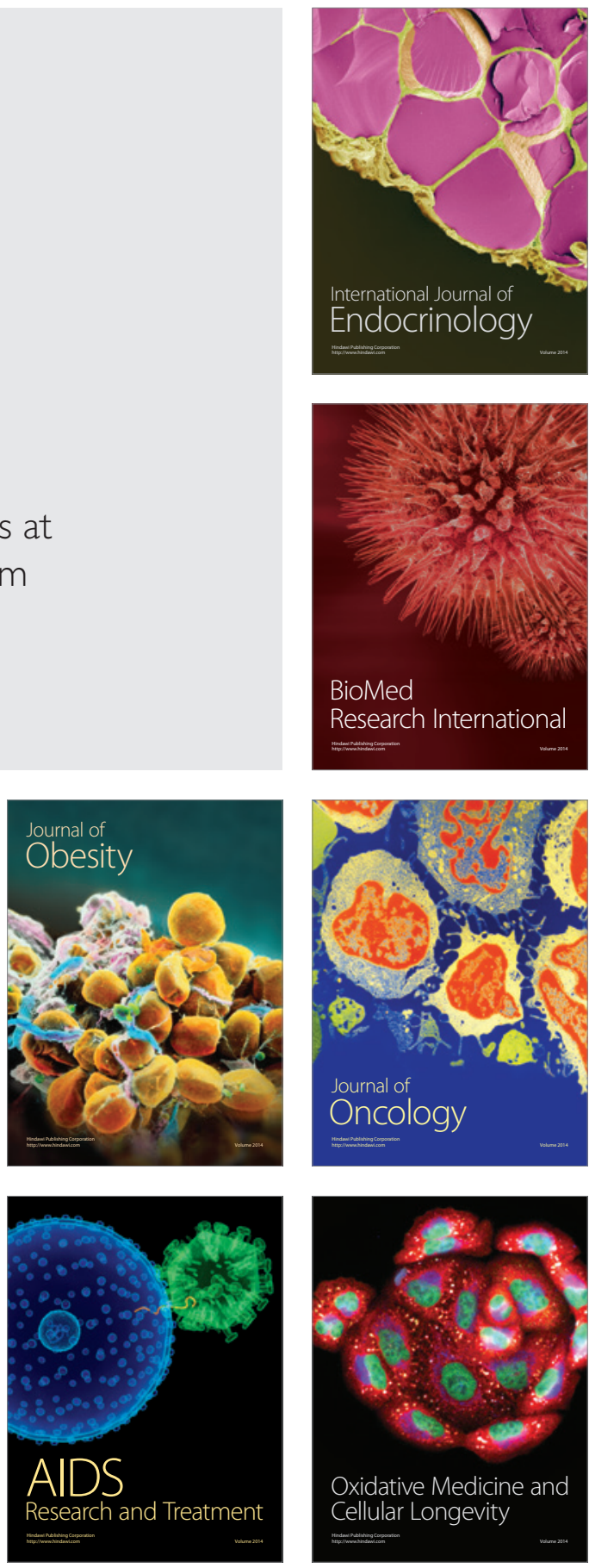